\section{EMERGENCY CONTRACEPTION - AN UPDATE}

\section{P. Pradhan}

\section{INTRODUCITON}

Emergency Contraception (EC) works by inhibiting or delaying ovulation or by preventing implantation ${ }^{1}$. Despite some assertion to the contrary it is not itself a form of abortion ${ }^{2}$. It is also called post-coital contraception or morning after pill. To dispel the notion that these methods must be used immediately after unprotected intercourse or that the user must wait until morning to begin treatment it is more accurate to describe them as secondary contraception. Knowledge of $\mathrm{E}$ has improved over the past decade among the adults and teenagers in developed countries ${ }^{3}$ and slowly getting popular in developing countries. Methods of EC are less effective than on going contraceptive use. ${ }^{4,5}$. The historical evolution of EC regimen begins in the 1920s wilh the discovery that oestrogen containing ovarian extracts interferred with pregnancy in mammals ${ }^{6}$. Veterinarians were the first to apply this finding in dogs and horses. The first decumented case in human only appeared in mid 1960s when Physician in Netherlands applied the veterinary practice of post-coital oestrogen administration to a 13 year old girl who had been raped at mid-cycle ${ }^{8}$. Around the same time US researchers were investigating the efficacy of high dose oestrogen preparation. In early 1970 s a Canadian physician, Albert Yuzpe and colleagues observed that a single dose of $100 \mu \mathrm{g}$ of oestrogen along with $1 \mathrm{mg}$ of progestin dinorgestrel induced endometrial changes that were incompatible with implantation ${ }^{9}$. This is called Yuzpe method and is the standard method till now ${ }^{10}$. Overall this method prevents three out of four pregnancies that would have occurred if no treatment had been used, and has on excellent safety record. Improvements in EC and its safety and availability ae welcome as part of any stretagy to lower the rate of induced abortion. Mifepristone was found to be an effective alternative but a dose a $600 \mathrm{mg}$ disrupted the cycle considerably ${ }^{12,13}$. There was a short trial in EC using Danazole but it was found to be ineffective ${ }^{12}$

The new data on levonorgestrel is the most exciting recent development ${ }^{14}$. Levonorgestrel is available in several countries for occasional post coital contraception in packs containing $0.75 \mathrm{mg}$ tablet ${ }^{14}$ The levonorgestrel method with its lower failure rate, few side effects and virtual absence of contraindication ${ }^{15}$ will supersede other methods. The efficacy effects of this formulation as an alternative harmonal emergency contraceptive has been studied by WHO in HongKong ${ }^{16}$.

\section{OBJECTIVE}

This paper will describe the indication for EC, its administration, efficacy, safety and acceptability of various regimens.

EC is indicated to prevent pregnancy following unprotected intercourse ${ }^{4}$.

1. When there is contraceptive failure or misuse including;

* Condom rupture, slippage or misuse.

* Diaphragm or cap dislodgement, breakage, tearing or early removal

* Failed coitus interruptus eg ejaculation

\section{INDICATION FOR EC}

in vagina or external genitalia.

IUCD expulsion

* Miscalculation of the periodic abstinence method.

* Missed more than 2 tablets of oral combined pills

* Overdue more than 2 weeks for the next depo injection.

2. In cases of sexual assault.

3. When no contraception has been used

\section{REGIMENS}

EC may be divided into two types : Mechanical and Pharmacological.

Mechanical : The only mechanical type of $\mathrm{EC}$ is the copper intra uterine device (IUD) which can prevent pregnancy even when inserted upto 7 days after unprotected intercourse. Spermatotoxic copper ions are released and they also cause an inflammatory response that makes the endometrium unsuitable for implantation of fertilised ovum and affects its transport as well. A meta analysis of 20 studies of post coital insertion of copper IUDs reveals that the failure rate is $\leq 0.1 \%$. The IUD offers the additional advantage of contraceptive protection. However, this method is contraindicated in women suffering from or at risk of sexually transmitted diseases ${ }^{2-4,7}$. Recently the new frameless intrauterine device called GyneFix is in the market for interval, emergency and post abortion contraception. GyneFix has the lowest failure rate of all copper IUDS currently available. Its performance is further optimised by the atraumatic frameless design which consists of six copper sleeves each $5 \mathrm{~mm}$ long and approximately $2.2 \mathrm{~mm}$ in diameter threaded on a length of suture material. The upper and lower sleeves are crimped on to the suture thread to prevent the sleeves from sliding off. The total surface area of copper, including the inner and outer surface is $330 \mathrm{~mm}^{2}$. The proximal end of the thread is provided with a knot which is placed in the fundal myometrium with an inserter, at a controlled depth of $1.0 \mathrm{~cm}$ and acts as an anchoring system. Notably this GyneFix lacks plastic frame which minimises the side effects and discomfort experienced with conventional IUDS. Most women requesting emergency contraception are young an nulliparous. As GyneFix can be a first choice contraceptive in nulliparous women it is very suitable for them for continuous use Experience in the UK has shown the signification potential of GynaeFix for $\mathrm{EC}^{17}$. GyneFix could, therefore be a useful new contraceptive option.

Pharmacological : At least five regimen of pharmacological EC have been widely studied. All involved oral administration of various hormonal regimens. These include high dose oestrogen, progestin in the form of levonorgestrel taken in two doses 12 hours apart and started within 48 hours of unprotected intercourse and others which will be briefly described.

Trials are underway to examine the feasibility of vaginal administration.

\section{Combined oral contraceptive (Yuzpe} method)

This combined oestrogen and progestogen "yuzpe regimen" consisting of ethinyl oestradio $100 \mu \mathrm{g}$ plus levonorgestrel $0.5 \mathrm{mg}$ or $\mathrm{dl}$ norgestrel $1.0 \mathrm{mg}$ is the most comonly used $\mathrm{EC}^{10}$. The woman begins this regimen within 72 hours of uprotected coitus and takes half the treatment dose $(100 \mu \mathrm{g}$ ethinylestradiol and $0.5 \mathrm{mg}$ levonorgestrel) immediately and the other half of similar dose $12 \mathrm{~h}$. later. When started within $72 \mathrm{~h}$. of unprotected intercourse this regimen prevented about $75 \%$ of pregnancies that would have occurred without treatment ${ }^{4,11}$. One reason for the popularity of the yuzpe method is that the proportions of hormones used are present in several brand of ordinary combined oral contraceptive pils. 
Women using these pills as EC therefore take two pills as the first dose and then take two more pills after $12 \mathrm{~h}$. Some newer formulation of oral contraceptives have lower levels of hormones and women will have to take more than two pills at a time to receive comparable doses $^{4,9,11}$.

The combined oestrogen - progestogen method produces nausea and vomiting in about 50\% and $20 \%$ of women respectively, similar to those commonly experienced with short term use of combined oral contraceptive but otherwise has a good safety record. The WHO has stated that there are no contraindications ${ }^{18}$. However, the latest guidelines from the faculty of family planning and reproductive health care of the Royal college of obstetricians and Gynaecologists still regards a history of thromboembolism as a relative contraindication and migraine at presentation with a history of migraine with aura, an absolute contraindication $^{19,20}$; Other side effects are headache, breast tenderness, abdominal pain and dizziness. Nausea may be reduced by taking pills with food. Some clinicians also prescribe a concurrent antiemetic as dimenhydrinate or cyclinize hydrochloride.

\section{Mechanism of action of steroidal EC}

Several hypotheses have been proposed. Among these is a suggestion that a more rapid transport of fertilised ova through the oviduct is induced. Furthermore, biopsies show evidence of a retarded maturation of the endometrium; Basal vacuole is not found after the $4^{\text {th }}$ day of the secretary phase of the cycle. If, however, implantation has already taken place these steroidal methods of EC have no effect on the pregnancy.

\section{MIFEPRISTONE}

The progesterone dependency of the implanted blastocyst is a new target in fertility regulation. Antiprogestin bind competitively to endogenous progesterone receptors and nullify its effect.
Administration of the antiprogestin Mifepristone (RU 486) during the luteal phase of the mestrual cycle produces a dramatic drop in the plasma levels of endogenous progesterone and estradiol. Administration of antiprogestins during the mestrual cycles is closely related to interception of the bastocyst and is therefore included in post coital interception studies. Because of the interference with early gestation, termed post coital contragestion, this regimen fills the window from day 21 to 28 day of the cycle that is not covered by other means of EC. Antiprogestin can be used irrespective of time lapse following unprotected intercourse and regardless of the number of exposures. When antiprogestins are given in the luteal phase, uterine beeding resembling menstruation occurs in approximately 2 days. This occurs irrespective of the presence of an early conceptus and whether or not it has implanted. Since there are no known contraindication to the use of antiprogestin and because the prevention of unwanted pregnancy is so important to the individuals concerned, no exclusion criteria for age, body weight and general good health have been considered in recent studies ${ }^{18}$. Mifepristone as a potent antiprogesterone has been tested since early 1980 s for its abortifacient qualities. This regimen consists of $600 \mathrm{mg}$ of mifepristone taken in a single dose within $72 \mathrm{~h}$. after unprotected intercourse. Although the side effects are less compared to yuzpe regimen a dose of $600 \mathrm{mg}$ disrupts the cycle considerably ${ }^{12,13,19}$. Further dose finding studies ${ }^{21}$ have found lower dose to be effective but mifepristone is not widely available and unlikely to be in the near future because of its association with induced abortion.

\section{DANAZOL}

This is a synthetic progestin androgen. Danazo can also be used as an EC. An appropriate regimen consists of two dose of $400 \mathrm{mg}$ Danazole taken $12 \mathrm{~h}$ apart as with the yuzpe regimen. The advantage of Danazol are that

\begin{tabular}{|c|c|c|c|}
\hline \multicolumn{4}{|c|}{ P. Pradhan : Emergency Contraceptio } \\
\hline \multicolumn{4}{|c|}{ Table I Regimens for Emergency contraception } \\
\hline S.No & Regimen & Dose required & Timing of Administration \\
\hline 1. & $\begin{array}{l}\text { Mechanical } \\
\text { copper - IUD }\end{array}$ & One insertion & $\begin{array}{l}\text { Within } 7 \text { days of } \\
\text { unprotected sex }\end{array}$ \\
\hline 2. & $\begin{array}{l}\text { * Oestrogen Only } \\
\text { * Progestin Only } \\
\text { * Mifepristone } \\
\text { * Danazol }\end{array}$ & $\begin{array}{l}\mathbf{E}=\mathbf{5 0} \boldsymbol{\mu g} \\
\text { two doses of } \\
\text { Two tablets } \\
\\
\mathbf{E}=\mathbf{3 0} \boldsymbol{\mu g} \\
\text { Two doses of } \\
\text { Four Tablets } \\
2.5 \mathrm{mg} / \mathrm{dose} \\
10 \mathrm{mg} / \mathrm{dose} \\
10 \mathrm{mg} / \mathrm{dose} \\
\text { two doses of } \\
\text { one table. Tablet } \\
\text { Single dose of } \\
600 \mathrm{mg} \\
\text { Two dose of } \\
\text { Four tablets }\end{array}$ & $\begin{array}{l}\text { First dose within } 72 \mathrm{~g} \text {. of } \\
\text { unprotected intercourse } \\
\text { and IInd dose } 12 \mathrm{~h} \text {. later } \\
\text { Do } \\
\text { First dose within } 72 \text { of } \\
\text { unprotected sex, two } \\
\text { dose/day for } 5 \text { days } \\
\text { Within } 72 \text { h of unprotected } \\
\text { sex, second dose } 12 \mathrm{~h} \text { later. } \\
\text { Within } 72 \text { h of } \\
\text { Unprotected sex } \\
\text { First dose within } 72 \mathrm{~h} \text { of } \\
\text { unprotected } \\
\text { sex, second } 12 \mathrm{~h} \text {. later. }\end{array}$ \\
\hline
\end{tabular}

contraception exists. Furthermore these women will only come to service providers, who themselves are usually ignorant. There are still many doctors and nuirses who are not aware of the available forms of EC, let alone have the specialist knowledge required. (4) Mis conception : Many people including doctors and nurses wrongly believe that EC causes abortion. It is important to point out that EC is ineffective if implantation has already taken place.

Effectiveness : The risk of pregnancy with one act of intercourse ranges from approximately $0-26 \%$ depending upon the day of the cycle one is exposed to. Available data suggest effectiveness of EC to be $98 \% 7,14,15$. Making EC more easily obtainable does not harm and may reduce the rate of unwanted pregnancy ${ }^{22}$.

its side effects are less severe than those associated with the yuzpe regimen and that danazol can be taken by women in whom combined oral contraceptives or oestrogen are contraindicated. The disadvantages are that there is less information available regarding this regimen and some data indicate a lack of efficacy $^{7,12,18}$. Table I sumnarises the various regimen of $\mathrm{EC}$.

\section{ACCEPTABILITY}

In countires where EC is offered its acceptability varies widely. Factors determining acceptability include regulation and legislation controlling the method, availability, providers knowledge and women's knowledge, religion, attitudes and practices ${ }^{2,4,7^{\prime}}$.

Knowledge of EC has improved over the past decade among the adults and teenagers in the developed world. However it is not widely used as should be, specially in developing world. It may be due to (1) Ignorance in the community : Many women are unware that such form of

\section{CONCLUSION}

Many women at risk of pregnancy may find themselves in need of EC. Millions of unwanted pregnancies could be averted if EC were widely accessible. The potential users should know about it and when and where to obtain it Knowledge of the correct time limit for EC use is very important. Existing regimens are usually inexpensive, often consist simply of altere doses of widely available medications and have been used for decades. A more important issue regardless of the drug used is that sooner the treatment is taken the greater the effectiveness. Schools and media could be used more effectively to maximise the potential benefit of EC in teenagers. More teenagers are sexually active than previously reported, especially those who are low achievers academically. Most countries have no form of licensed preparation for EC but do have combined pills and in many these are available over the counter. This has implication for all service providers 
Progesterone pills are fare less available and often more expensive. If effectiveness is paramount an IUD is still the best option yet it is not routinely offered. What is needed is education and information for both health workers and women of all the possible options so that the best can be chosen. EC will continue to develop. The population council is doing further work on the long established oestrogen - Progestogen method to try to reduce the side effects through limiting the dose or substituting a different progestogen. The WHO is looking at single dose levonorgestrel and further Mifepristone regimen; and family health internationa is investigating routine use of antiemetics in the oestrogen-progestogen regimen. We should welcome new methods of EC especially if they are more effective and acceptable. The greater the choice of the regimens and venues to obtain treatment, the greater is the chance of those in need obtaining it.

\section{REFERENCES:}

1. Glasier A. Emegency postcoital contraception. N. Eng. J. Med. 1997;337:1058-64

2. Grimes DA. Emergency Contraception Expanding Opportunities for Primary Prevention. N. Eng. J.Med. Opportunities for P

3. Graham A, Green L, Glasier AF. Teenagers Knowledge of emergency contraception : questionnaire survey in south east scotland. BMJ. 1996;312:1567-9.

4. Ellerson C. history and efficacy of emergency contraception beyond coco cola. International family planning prospectives. 1996; 22: 52-56.

5. Bellagio conference on emergency contraception. Consensues statement on emergency contraception Contraception 1995: 52: 211-213.

6. Affandi B. Emergency contraception : What is it ? Med. J. Indonesia 1997 ; 6: 243 - 48.

Affandi B. Emergency contraception. Jr. of Paediatrics Obstetrics and Gynaecology 1999; 25:33-37.

8. Jha, R. Singh M. Emergency Contraception. Gynaecology and obstetrics Health Letter. Vol I. No. 2 1999: 13-14.

9. Yuzpe AA, Lancee $\mathrm{Wj}$, Ethynylestradiol and dinorgestrel as a post - coital contraception. Ferti sterl 1997; 28:932-36.

10. Yuzpe AA, Percival Smith RK, Rademaker AW, A multicenter clinical investigation employing ehinglestradiol combine with all - norgestrel as a past coital contraceptive agent. Forti Sterial 1982 . 37:508-13.

11. Trussel J, Rodriguez G. New estimates of the effectiveness of the Yuzpe regimen of Emergency contraceptive. Contraception 1998; 57:363-9.

12. Webb, ANC. Russel, J. Elstein, H. Comparision of Yuzperegimen, Danazol Mifepristone AND (RU486) in oral post coital contraception. BMJ ; 1992; 305: in oral post

13. Glasier A, Thong K. J. Dewar M, Mackie M. Baird DT. Mifepristone (RU486) compared with high doSe oestrogen and Progestogen for emergency Post - coital contraception. N. Eng. J. Med. 1992; 327 : 1041-4. 4. Task force on post ovulatory methods of fertility regulation Randomised controlled trial of levonorgestrel versus of Yuzpe regimen of combined oral contraception for emergency contraception Lancet 1998; 352:428-33.

15. Guikkebabd J. Commentary. Time for Emergency contraception with levonorgestrel alone. Lancet 1998 ; 352:416.

16. HO, PC, Kwan MSW. A prospective randomised comparision of levonorgestreal with the Yuzpe regimen in post coital contraception. Human report $1993 ; 8: 389-92$

17. Dennis J, Webb A, Joung J. The first UK centre to introduce the new GynaeFix Intrauterine Implant. Problem encountered and client satisfaction in over 200 Insertion.Results of multicentre study presented at the $4^{\text {th }}$ congress of the European society of contraception. Prague, June 1998.

18. World health organisation. Improving access to quality care in family planning ; Medical eligibility criteria for initiating and continuing use of contraceptive methods. Geneva. WHO $1999 ; 318$ $342-3$

19. Webba A. Emergency contraception: Is it time to change method ? BMJ 1999;318:342 - 3 .

20. Kubba A, Wilkinson C. Recommendation for clinical practice: Emergency contraception. London, Faculty of farily proney cont the R COG, 1998 .

21. HRP/UNDP/UNFPA/WHO World Bank Special programme of Research. Development and Research Training in human reproduction. Annual technical
report. Geneva. WHO. 1996 . 22. Ge $\mathrm{A}$. Baid D. The effecto

22. Glasier A. Baird D. The effect of self administering Emergency contraception. N. ENG. J. MED. 1998

\section{JNMA MYSTERY}

Case \# 1

A 28 year old man from Sankuwasabha presented with 5 years of gradually progressive weakness.

He was completely well until 5 years before when he began to experience slight weakness in the legs. This progressed, and by 18 months before he was unable to walk independently. He noticed slight parasthesias of the feet. The arms seemed to be normal. There was no bowel or bladder dysfunction. Over this 5year period, he had gradually experienced hearing loss. There was no visual disturbance, headaches, or back pain.

He had worked as a farmer and drank alcohol moderately. There was no known history of trauma nor of TB or known TB contact. Immunization history was unknown. Diet had limited intake of fruits, but he did take meat and eggs. His younger sister had recently begun to experience similar symptoms at the age of 22 .

On exam he spoke with slightly slurred speech and was markedly hard of hearing. Vital signs, chest, and abdomen were normal. The back appeared normal. His neuro exam was remarkable for $3 / 5$ power in all groups of the legs; normal power in the arms. In the legs, tone was slightly increased, but reflexes markedly diminished, and plantars downgoing. Sensory exam was made difficult by his loss of hearing.

Labs CSF, X-ray spine were normal. Na 150, K 5.1, Creatinine 1.5, Het $49 \%$, CPK 89.

(1) What is your differential diagnosis for this man's weakness?

(2) If you can only do one test to make the diagnosis, what will it be?

(3) What is the most likely diagnosis?

$\begin{array}{ll}\text { Send answers to } & \begin{array}{l}\text { Mark Zimmerman, MD } \\ \text { Patan Hospital } \\ \text { Box 252 }\end{array}\end{array}$

Correct answer to be published in next issue JNMA. 